\title{
Phillipsins A and B from Zingiber phillippsii Mood \& Theilade in Borneo
}

\section{Takashi Kamada $^{\oplus 1^{*}}$, Julius Kulip ${ }^{\oplus 1}$, Kazuki Tani ${ }^{\circledast 1}$, Chin-Soon Phan ${ }^{\oplus 1}$, Kishio Hatai $^{\odot 2}$ and Charles S. Vairappan ${ }^{\odot 1}$}

\author{
${ }^{1}$ Laboratory of Natural Products Chemistry, Institute for Tropical Biology and Conservation, \\ Universiti Malaysia Sabah, 88400 Kota Kinabalu, Sabah, Malaysia \\ ${ }^{2}$ Microbiology and Fish Disease Laboratory, Borneo Marine Research Institute, Universiti \\ Malaysia Sabah, 88400 Kota Kinabalu, Sabah, Malaysia
}

(Received September 03, 2017; Revised November 1, 2017; Accepted November 11, 2017)

\begin{abstract}
Two new aromatic compounds, phillipsins A (1) and B (2) were isolated from the Bornean wild ginger Zingiber phillippsii Mood \& Theilade, and were characterized based on spectroscopic data (HRESI-MS, FTIR as well as 1D and 2D NMR). These metabolites also exhibited strong antifungal activity against selected fungi.
\end{abstract}

Keywords: Zingiber phillipsii; ginger; antifungal; chemotaxonomical marker; Borneo. (C) 2017 ACG Publications. All rights reserved.

\section{Introduction}

The native species of ginger Zingiber phillippsii belongs to the family Zingiberaceae and is distributed throughout Southeast Asian countries, and it is traditionally believed to contain high medicinal value [1]. This species is widely used in traditional herbal medicine by the local Dusun community in Sabah, Malaysia [2,3]. It is a known that ginger has been used by indigenous people in Borneo for various treatment including respiratory and gastrointestinal diseases. In addition, local traditional knowledge also attributes ginger to have antiemetic, anti-flatulence, anti-diarrhea, cardiotonic and expectorant as well as to cure swollen body and snake bite $[4,5]$. Generally, ginger has been reported to contain diverse bioactive secondary metabolites from terpenoids to aromatic compounds [6-11]. The secondary metabolites isolated from ginger have been reported to exhibit antifungal potentials $[10,11]$. Therefore, we decided to test the isolated compounds against marine Oomycetes (lower fungi) that infects and causes disease outbreak in mud crab juveniles, Scylla tranquebarica, that have severely affected the mud crab production in Sabah, Malaysia [12]. The

*Corresponding author: E-Mail: takashi.kamada@ums.edu.my; Phone: +60-88-320-000/ 2370 
possible and potent causative agents for this issue were the lower fungi of genera Lagenidium and Haliphthoros [13]. In addition, there are no scientific reports for the chemical constituents of $Z$. phillippsii. Therefore, as part of our continuous effort to search for novel bioactive compounds from natural sources [14], we have isolated and elucidated chemical structures of two new compounds, phillipsins A (1) and B (2) from Z. phillippsii. Herein, we describe the isolation, structural determination and antifungal potential of these new metabolites.

\section{Materials and Methods}

\subsection{General Experimental Procedures}

Polarimeter AUTOPOL IV (Rudolph Research Analytical) was used to measure the value of optical rotations. FTIR spectrometer (Thermo Nicolet Nexus) was used to obtain IR data. ECA 600 NMR spectrometer (JEOL) was used to acquire spectra in $\mathrm{CDCl}_{3}$ with TMS as the internal standard. LCMS-IT-TOF (Shimadzu) was used to obtain high resolution mass spectra. Column chromatography as well as preparative and analytical TLC were performed utilizing normal phase silica gel (Merck, Kieselgel 60, 70-230 mesh), normal phase silica gel precoated glass plate (Merck Kieselgel $60 \mathrm{~F}_{254}$ ) and silica gel precoated aluminum sheet (Merck, Kieselgel $60 \mathrm{~F}_{254}$ ), respectively.

\subsection{Biological Materials}

Specimens of Z. phillippsii were collected from Tudan Village, Sabah, Malaysia $\left(05^{\circ} 86.730^{`} \mathrm{~N}\right.$, $116^{\circ} 32.591$ 'E) on September 2015 and identified by the second author. The voucher specimen (BORH1050JK) was stored in the BORNEENSIS Collection of Institute for Tropical Biology and Conservation, University of Malaysia Sabah.

\subsection{Extraction and Isolation}

Partially dried ginger rhizome ( $200 \mathrm{~g}$ ) was rinsed in three changes of distilled water, air dried, chopped and soaked in $70 \%$ aqueous ethanol for 5 days. The resulting ethanol extract was filtered, concentrated, and liquid-liquid extraction between ethyl acetate $(\mathrm{EtOAc}) / \mathrm{H}_{2} \mathrm{O}$. The organic layer was washed by double $\mathrm{H}_{2} \mathrm{O}$ and moisture was removed under anhydrous $\mathrm{Na}_{2} \mathrm{SO}_{4}$. After evaporation step, a dark green oil $(687.0 \mathrm{mg})$ was collected. This crude extract was separated by conventional column chromatography using gradient solvent system utilizing combination of hexane and EtOAc to produce five fractions, while total of $77.0 \mathrm{mg}$ of fraction 2 eluted by hexane-EtOAc (8:2) and further purified via preparative TLC with toluene to acquire $\mathbf{1}(14.4 \mathrm{mg})$ and $\mathbf{2}(10.8 \mathrm{mg})$.<smiles>CCC=CCCOC(=O)C=Cc1ccc(OC)cc1</smiles><smiles>CC/C=C/CCOC(=O)/C=C\c1ccc(OC)cc1</smiles>

Figure 1. Structures of compounds $\mathbf{1}$ and 2. 


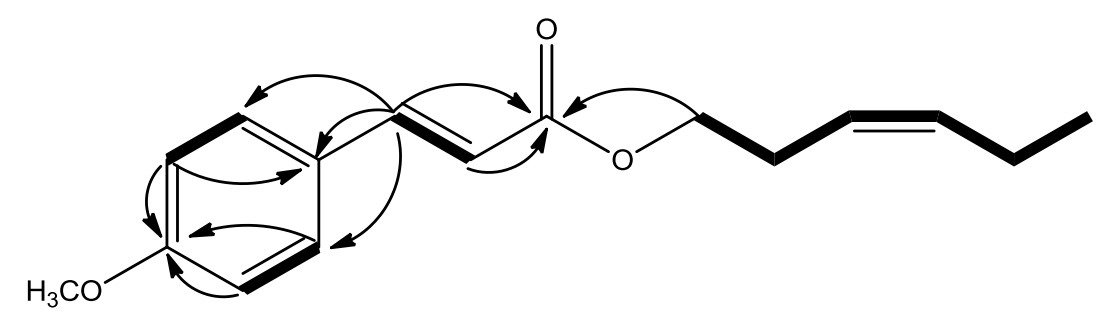

Figure 2. ${ }^{1} \mathrm{H}-{ }^{1} \mathrm{H}$ COSY and selected $\mathrm{HMBC}$ correlation of compound $\mathbf{1}$.

Phillipsin A (1): colorless oil; $[\alpha]_{D}^{25}:+5.3\left(\mathrm{c} 0.30, \mathrm{CHCl}_{3}\right.$ ); IR (neat) $v_{\max } 1706$ and $1603 \mathrm{~cm}^{-1} ;{ }^{1} \mathrm{H}$ and ${ }^{13} \mathrm{C}$ NMR data, Table1; HRESI-MS $m / z 261.1478[\mathrm{M}+\mathrm{H}]^{+}$(calculated for $\mathrm{C}_{16} \mathrm{H}_{21} \mathrm{O}_{3}, 261.1485$ ) and $283.1282[\mathrm{M}+\mathrm{Na}]^{+}$(calcd for $\mathrm{C}_{16} \mathrm{H}_{20} \mathrm{O}_{3} \mathrm{Na}, 283.1305$ ).

Phillipsin B (2): colorless oil; $[\alpha]_{D}^{25}:+13.3\left(\mathrm{c} 0.15, \mathrm{CHCl}_{3}\right.$ ); IR (neat) $v_{\max } 1699$ and $1612 \mathrm{~cm}^{-1} ;{ }^{1} \mathrm{H}$ and ${ }^{13} \mathrm{C}$ NMR data, Table1; HRESI-MS $m / z$ 261.1486 [M + H] $]^{+}$(calculated for $\mathrm{C}_{16} \mathrm{H}_{21} \mathrm{O}_{3}, 261.1485$ ) and $283.1284[\mathrm{M}+\mathrm{Na}]^{+}$(calcd for $\mathrm{C}_{16} \mathrm{H}_{20} \mathrm{O}_{3} \mathrm{Na}, 283.1305$ ).

\subsection{Biological Assay}

Antifungal bioassay was conducted based on the slight modification from standard method reported by Munchan et al. [15]. The minimum inhibitory concentration (MIC) of fungistatic effect on hyphae were carried out by incorporating the compound solutions $(100,50,25,12.5 \mu \mathrm{g} / \mathrm{mL})$ onto PYGS agar in petri dish followed by agar block inoculation of fungi strains Fusarium moniliforme NJM 8995, Fusarium oxysporum NJM 0179, Fusarium solani NJM 8996, Haliphthoros milfordensis IPMB 1603, Haliphthoros sabahensis IPMB 1402 and Lagenidium thermophilum IPMB 1401 via advance edge cut with No. 2 cork borer. The MIC was determined visually as the lowest concentration showing no hyphal growth when they were incubated at $25{ }^{\circ} \mathrm{C}$ for 3 and 7 days. The control was sterilized seawater solution without compounds.

\section{Results and Discussion}

\subsection{Structure Elucidation}

Partially dried specimens of Z. phillippsii, were extracted in ethanol, after chromatographic techniques, phillipsins A (1) $(2.1 \%$ on crude extract weight) and B (2) $(1.6 \%)$ were afforded from crude extract as shown in Figure 1. Compound $\mathbf{1}$ was isolated as colourless oil. The molecular formula of 1 was elucidated as $\mathrm{C}_{16} \mathrm{H}_{20} \mathrm{O}_{3}$ with seven degrees of unsaturation as deduced from HRESI-MS, $\mathrm{m} / \mathrm{z}$ 261.1478 $[\mathrm{M}+\mathrm{H}]^{+}$(calcd for $\mathrm{C}_{16} \mathrm{H}_{21} \mathrm{O}_{3}, 261.1485$ ) and $283.1282[\mathrm{M}+\mathrm{Na}]^{+}$(calcd for $\mathrm{C}_{16} \mathrm{H}_{20} \mathrm{O}_{3} \mathrm{Na}$, 283.1305). The IR spectrum displayed absorption bands indicating carbonyl $\left(1706 \mathrm{~cm}^{-1}\right)$ and aromatic $\left(1603 \mathrm{~cm}^{-1}\right.$ ) functionalities. The ${ }^{1} \mathrm{H}$ and ${ }^{13} \mathrm{C}$ NMR spectra (Table 1) showed signals of methoxyl protons at $\delta 3.84\left(3 \mathrm{H}, \mathrm{s}, 4^{\top}-\mathrm{OMe}\right)$ and two pairs of aromatic protons at $\delta 7.47(2 \mathrm{H}, \mathrm{d}, J=8.9 \mathrm{~Hz}, \mathrm{H}-$ $3^{\prime}$ and $\left.5^{\prime}\right)$ and $6.90\left(2 \mathrm{H}, \mathrm{d}, J=8.9 \mathrm{~Hz}, \mathrm{H}-2^{\prime}\right.$ and $\left.6^{\prime}\right)$. In addition, these two pairs of benzylic protons were one bond correlated to two pairs of overlapped carbon signals at $\delta 130.4$ and 115.0 suggested the presence of a benzene system with para substitution. While the remaining carbon signals were carbonyl $\left(\delta 168.1, \mathrm{C}^{\prime} 9^{\prime}\right)$, four olefinic methines, three methylenes (including a hydroxymethylene carbon $(\delta 64.6, \mathrm{C}-1))$ and an aliphatic methyl group as attributed by HSQC and DEPT-135. Construction of planar structure of 1 based on ${ }^{1} \mathrm{H}-{ }^{1} \mathrm{H}$ COSY correlations and key HMBC 
correlations are shown in Figure 2. The cross peaks of ${ }^{1} \mathrm{H}-{ }^{1} \mathrm{H}$ COSY revealed the connectivity for the four partial structures $\mathrm{H}^{-2} / \mathrm{H}-3^{\prime}, \mathrm{H}-5^{\prime} / \mathrm{H}-6^{\prime}, \mathrm{H}-7^{\prime} / \mathrm{H}-8^{\prime}$ and $\mathrm{H}_{2}-1 / \mathrm{H}_{2}-2 / \mathrm{H}-3 / \mathrm{H}-4 / \mathrm{H}_{2}-5 / \mathrm{H}_{3}-6$. The $\mathrm{HMBC}$ cross peak between 4'-OMe and C-4' were important key to confirm 1,4-disubstituted phenyl moiety. The two partial structures of C-7' to C-8' and C- 1 to C-6 were connected through the ester linkage from HMBC interactions of $\mathrm{H}-7$ ', $\mathrm{H}-8$ ' and $\mathrm{H}_{2}-1$ to C-9'. The downfield shift of $\mathrm{H}_{2}-1$ resonance at $\delta 4.19$ suggested directly bonded to an oxygenated atom. Whereby, the side chain hex-3-en-1-yl propanoate unit was attached to C-1' based on HMBC correlations of H-7' to C-1', C-2' and C-6'; and H-2' and H-6' to C-7'.

The relative stereochemistry was determined by NOESY experiments and coupling constant values. The large coupling constant values between $\mathrm{H}^{-} 7^{\prime} / \mathrm{H}-8^{\prime}$ was $15.8 \mathrm{~Hz}$, suggested $E$-configuration double bonds at C-7'/C-8'. The lack of NOE correlations between $\mathrm{H}-7^{\prime} / \mathrm{H}-8^{\prime}$ further supported this configuration. While, olefin at C-3/C-4 was determined as Z-configuration based on coupling constant ${ }^{3} J_{3-4}=10.7 \mathrm{~Hz}$. Thus, the structure of 1 was identified as $(E)-(Z)-3$-(4-methoxyphenyl) hex-3-en-1-yl acrylate.

Table 1. ${ }^{1} \mathrm{H}$ and ${ }^{13} \mathrm{C}$ NMR data for 1 and $2\left(600\right.$ and $150 \mathrm{MHz}$ in $\mathrm{CDCl}_{3}, \delta$ in ppm, $J$ in $\mathrm{Hz}$ ).

\begin{tabular}{ccccc}
\hline & \multicolumn{2}{c}{$\boldsymbol{\delta}_{\mathbf{C}}$} & \multicolumn{2}{c}{$\boldsymbol{\delta}_{\mathbf{H}}(\mathbf{m u l t} ., \boldsymbol{J}$ in Hz) } \\
\cline { 2 - 5 } Position & $\mathbf{1}$ & $\mathbf{2}$ & $\mathbf{1}$ & $\mathbf{2}$ \\
\hline 1 & 64.6 & 64.4 & $4.19 \mathrm{t}(6.9)$ & $4.12 \mathrm{t}(6.9)$ \\
2 & 27.6 & 27.4 & $2.46 \mathrm{q}(6.9)$ & $2.39 \mathrm{q}(6.9)$ \\
3 & 124.5 & 124.5 & $5.38 \mathrm{td}(6.9,10.7)$ & $5.31 \mathrm{td}(6.9,10.3)$ \\
4 & 135.3 & 135.2 & $5.52 \mathrm{td}(6.9,10.7)$ & $5.50 \mathrm{td}(6.9,10.3)$ \\
5 & 21.3 & 21.3 & 2.09 quintet $(6.9)$ & 2.05 quintet $(6.9)$ \\
6 & 15.0 & 14.9 & $0.98 \mathrm{tt}(6.9)$ & $0.96 \mathrm{t}(6.9)$ \\
$1^{\prime}$ & 127.9 & 128.1 & & \\
$2^{\prime}$ & 130.4 & 132.8 & $7.47 \mathrm{~d}(8.9)$ & $7.68 \mathrm{~d}(8.9)$ \\
$3^{\prime}$ & 115.0 & 114.1 & $6.90 \mathrm{~d}(8.9)$ & $6.87 \mathrm{~d}(8.9)$ \\
$4^{\prime}$ & 162.0 & 161.1 & & \\
$5^{\prime}$ & 115.0 & 114.1 & $6.90 \mathrm{~d}(8.9)$ & $7.87 \mathrm{~d}(8.9)$ \\
$6^{\prime}$ & 130.4 & 132.8 & $7.47 \mathrm{~d}(8.9)$ & $6.84 \mathrm{~d}(12.9)$ \\
$7^{\prime}$ & 145.1 & 144.0 & $7.63 \mathrm{~d}(15.8)$ & $5.82 \mathrm{~d}(12.4)$ \\
$8^{\prime}$ & 116.3 & 117.8 & $6.30 \mathrm{~d}(15.8)$ & \\
$9^{\prime}$ & 168.1 & 167.1 & & $3.83 \mathrm{~s}$ \\
$4^{\prime}-$ OMe & 56.1 & 56.0 & $3.83 \mathrm{~s}$ & \\
\hline
\end{tabular}

Compound 2 was obtained as a colorless oil. The molecular formula of $\mathrm{C}_{16} \mathrm{H}_{20} \mathrm{O}_{3}$ was obtained on the basis of high resolution mass spectrum with $[\mathrm{M}+\mathrm{H}]^{+}$ion at $\mathrm{m} / z 261.1486$ (calcd for $\mathrm{C}_{16} \mathrm{H}_{21} \mathrm{O}_{3}$, 261.1485) and $[\mathrm{M}+\mathrm{Na}]^{+}$psedomolecular ion at $\mathrm{m} / \mathrm{z} 283.1284$ (calcd for $\mathrm{C}_{16} \mathrm{H}_{20} \mathrm{O}_{3} \mathrm{Na}, 283.1305$ ). Similar significant fragment ions in the mass spectrum, comparable absorption bands in the IR spectra and similar chemical shifts in the ${ }^{1} \mathrm{H}$ and ${ }^{13} \mathrm{C}$ NMR spectra (Table 1) indicated $\mathbf{1}$ and $\mathbf{2}$ to be stereoisomers. Comparison of 1D NMR data (Table 1) of $\mathbf{2}$ with those of $\mathbf{1}$, revealed the double bond at C-7'/C-8' had Z-configuration instead of $E$-configuration was due to smaller coupling constant ${ }^{3} J_{7^{\prime}}$. $8^{\prime}=12.4 \mathrm{~Hz}$. Furthermore, H-7' showed NOE correlation to H-8', supported the Z-configuration of double bond at C-7'/C-8'. Whereas, double bond at C-3/C-4 had Z-configuration was due to ${ }^{3} J_{3-4}=10.3$ Hz. Hence, compound 2 was reported as (Z)-(Z)-3-(4-methoxyphenyl) hex-3-en-1-yl acrylate.

Compounds 1 and $\mathbf{2}$ were screened against six fungal strains from marine such as $F$. moniliforme, $F$. oxysporum, $F$. solani, $H$. milfordensis, $H$. sabahensis and L. thermophilum as shown in Table 2. The MIC indicated the fungistatic effect on hyphae by these compounds. Metabolites $\mathbf{1}$ and 2 were most active against $H$. milfordensis and $L$. thermophilum at concentrations of $25 \mu \mathrm{g} / \mathrm{mL}$. 
Table 2. MICs of compounds $\mathbf{1}$ and $\mathbf{2}$ against six strains of marine fungi.

\begin{tabular}{lcc}
\hline \multicolumn{1}{c}{ Strains } & \multicolumn{2}{c}{ MIC $(\boldsymbol{\mu g} / \mathbf{m L})$} \\
\cline { 2 - 3 } \multicolumn{1}{c}{ F. moniliforme } & $>50$ & $\mathbf{2}$ \\
F. oxysporum & $>50$ & $>50$ \\
F. solani & $>50$ & $>50$ \\
H. milfordensis & 25 & 50 \\
H. sabahensis & 50 & 25 \\
L. thermophilum & 25 & 50 \\
Positive control: Itraconazole with MIC $3.2 \mu \mathrm{g} / \mathrm{mL}$. & 25 \\
\hline
\end{tabular}

The genus Zingiber consists of 210 species worldwide but not all species have been chemically evaluated. Among the chemically studied species, various chemical structures have been determined including, diarylheptanoids, flavonoids, phenolics, phenylbutenoid and terpenoids. In our study, a total of two aromatic new compounds $\mathbf{1}$ and $\mathbf{2}$ were isolated as its major metabolites from $Z$. phillippsii that may be used for their chemical defense. The structures of isolated chemicals were closely related to the gingerol and shogaol analogues [16,17]. These compounds will be used as an important chemotaxonomical marker for the East Malaysian Z. phillippsii. Hence, the present study represents an important milestone in chemotaxonomical evaluation of the genus Zingiber.

\section{Acknowledgments}

This work was supported by Universiti Malaysia Sabah [SBK0278-STWN-2016] and Matsuken Kogyo Corporation [GL00155]. Authors would like to thank Mr. Hendry Charles (Pemborong Mangkab Enterprise Sdn. Bhd.) for his kind assistance to make test type bioproducts. The authors would like thank Mr. Takafumi Ishikawa and Ms. Liang Wei, Hokkaido University, for their kind assistance during data comparison.

\section{Supporting Information}

Supporting Information accompanies this paper on http://www.acgpubs.org/RNP

\section{ORCID}

Takashi Kamada: 0000-0002-2886-4623

Julius Kulip: 0000-0003-3893-9833

Kazuki Tani: 0000-0002-2760-3771

Chin-Soon Phan: 0000-0002-6500-696X

Kishio Hatai: 0000-0003-3343-350X

Charles S. Vairappan: 0000-0001-7453-1718

\section{References}

[1] A.Y. Koga, F.L. Beltrame and A.V. Pereira (2016). Several aspects of Zingiber zerumbet: A review, Re. Bras. Farmacogn. 26, 385-391.

[2] J. Kulip (2007). Common medicinal plants of Sabah, Sepilok Bulletin. 6, 1-23.

[3] J. Kulip (2007). Gingers in Sabah and their traditional uses, Sepilok Bulletin. 7, 23-44. 
[4] C.E. Ficker, J.T. Arnason, P.S. Vindas, L.P. Alvarez, K. Akpagana, M. Gbéassor, C. De Souza and M.L. Smith (2003). Inhibition of diverse pathogenic fungi by ethnobotanically selected plant extracts, Mycoses. 46, 29-37.

[5] I. Gómez-Betancur and D. Benjumea (2014). Traditional use of the genus Renealmia and Renealmia alpinia (Rottb.) Maas (Zingiberaceae)-a review in the treatment of snakebites, Asian Pac. J. Trop. Med. 7, S574-582.

[6] M. Afzal, D. Al-Hadidi, M. Menon, J. Pesek and M.S. Dhami (2001). Ginger: An ethnomedical, chemical and pharmacological review, Drug Metabol. Drug Interact. 18, 159-190.

[7] K. Akiyama, H. Kikuzaki, T. Aoki, A. Okuda, N.H. Lajis and N. Nakatani (2006). Terpenoids and a diarylheptanoid from Zingiber ottensii, J. Nat. Prod. 69, 1637-1640.

[8] R.D. Hiserodt, S.G. Franzblau and R.T. Rosen (1998). Isolation of 6-, 8-, and 10-gingerol from ginger rhizome by HPLC and preliminary evaluation of inhibition of Mycobacterium avium and Mycobacterium tuberculosis, J. Agric. Food Chem. 46, 2504-2508.

[9] K. Toume, M. Sato, T. Koyano, T. Kowithayakom, T. Yamori and M. Ishibashi (2005). Cytotoxic dimeric sesquiterpenoids from Curcuma parviflora: isolation of three new parviflorenes and absolute stereochemistry of parviflorenes A, B, D, F, and G, Tetrahedron. 61, 6700-6707.

[10] M. Aghazadeh, A. Zahedi Bialvaei, M. Aghazadeh, F. Kabiri, N. Saliani, M. Yousefi, H. Eslami and H. Samadi Kafil (2016). Survey of the antibiofilm and antimicrobial effects of Zingiber officinale (in vitro study), Jundishapur J. Microbiol. 9, e30167.

[11] A.Y. Koga, F.L. Beltrame and A.V. Pereira (2016). Several aspects of Zingiber zerumbet: a review, Rev. Bras. Farmacogn. 26, 385-391.

[12] C.R. Lavilla-Pitogo and L.D.D. Peña (2004). Diseases in farmed mud crabs, Scylla spp.: diagnosis, prevention, and control, Aquaculture Department Southeast Asian, Fisheries Development Center, Iloilo.

[13] K. Hatai (2012). Diseases of fish and shellfish caused by marine fungi, In: Biology of Marine Fungi, Progress in Molecular and Subcellular Biology, ed: C. Raghukumar, Springer, Heidelberg, Germany, pp.15-52.

[14] T. Ishii, H. Matsuura, K. Kaya and C.S. Vairappan (2011). A new bisabolane-type sesquiterpenoid from Curcuma domestica, Biochem. Syst. Ecol. 39, 864-867.

[15] C. Munchan, K. Hatai, S. Takagi and A. Yamashita (2009). In vitro and in vivo effectiveness of itraconazole against Ochroconis humicola isolated from fish, Aquaculture Sci. 57, 399-404.

[16] M.H. El-Naggar, A. Mira, F.M. Abdel Bar, F. Shimizu, M.M. Amer and F.A. Badria (2016). Synthesis, docking, cytotoxicity, and LTA4H inhibitory activity of new gingerol derivatives as potential colorectal cancer therapy, Bioorg. Med. Chem. 25, 1277-1285.

[17] S.K. Jo, I.S. Kim, S.U. Rehman, S.K. Ha, H.Y. Park, Y.K. Park and H.H. Yoo (2016). Characterization of metabolites produced from the biotransformation of 6-shogaol formed by Aspergillus niger, Eur. Food Res. Technol. 242, 137-142.

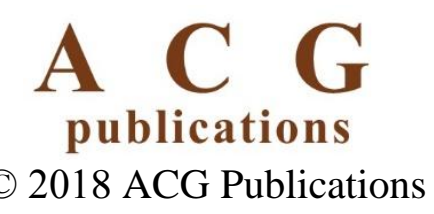

